\title{
Proposing Multiple-Criteria Ranking to Simulate Building Renovation in Cities
}

\author{
Arjun Jamil ${ }^{*}$, Nils Weiss, Thomas Preisler, Wolfgang Renz ${ }^{*}$ \\ Faculty of Engineering and Computer Science, Hamburg University of Applied Sciences, Berliner Tor 7, 20099 Hamburg, \\ Germany; * \{arjun.jamil, wolfgang.renz\}@haw-hamburg.de
}

SNE 30(1), 2020, 7 - 10, DOI: 10.11128/sne.30.sn.10502

Received: May 10, 2019 (Selected ASIM SST Hamburg 2018

Postconf. Publ.), Accepted: October 10, 2019

SNE - Simulation Notes Europe, ARGESIM Publisher Vienna ISSN Print 2305-9974, Online 2306-0271, www.sne-journal.org

Abstract. Building renovation plays a huge role in reducing $\mathrm{CO} 2$ emissions and energy demand. To understand the effects of different renovation strategies, expert users and decision makers need to explore renovation scenarios both spatially and temporally. The ongoing GEWISS project aims to do this by providing a GIS (Geographical Information System) to visualize energy demand per building as well as an interface to simulate possible renovation paths to its users. This white paper presents a novel proposal to simulate future renovation paths by utilizing different user scenarios containing multiple selection criteria to rank current building stock and consequently use optimization to pass them through the user selected renovation strategy in the most optimal way.

\section{Introduction}

Existing building stock contributes to up to $40 \%$ of the EU's total CO2 emissions [1]. Renovation of building stock to national standards such as the German energy saving ordinance (EnEV 2014) is critical to reducing Germany's carbon footprint and energy usage. The GEWISS (Geographical Heat Information and Simulation System, 2014-2019, (http://gewiss.haw-hamburg.de/)) project aims to analyse and visualise heating demand and $\mathrm{CO} 2$ emissions based on the existing building stock of cities and to construct an expert tool that would help decision makers to simulate different scenarios and find the ones that would have the maximum cost effectiveness in reducing emissions and heating demand [2].

As can be seen from its contribution to the Hamburg Wärmekataster [3], the GEWISS project approaches the problem in a spatial context, effectively making it a GIS tool with additional simulation support. Another question that the decision makers in Hamburg would like to explore is the organic expansion of district heating grids in Hamburg; the GEWISS project is expected to provide insights on which areas are worth expanding into with the district heating grid. Hence the simulation ideally should also consider the district heating parameters. By knowing what future grid expansions might provide the best reduction in emissions and heating demand, the city can expand the grid in the most costefficient way.

Using classifications provided by third party project partners to the project, an underlying deterministic data model is created, one which contains select information of all current buildings in the city of Hamburg (Figure 1).

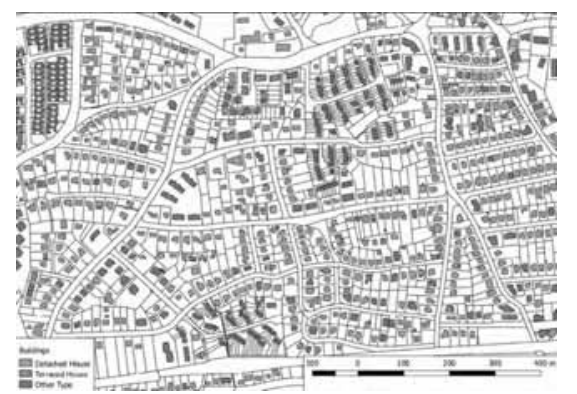

Figure 1: Map extract containing building geometry for each unique building (taken from [2]).

This data is obtained on the basis of the Hamburg ALKIS database [4] with an estimation of IWU building type [5] also for those $50 \%$ of houses where the building year is unknown [6].

Using building geometry as a metric, all the existing buildings are classified into different building types. These building types have standardised heating demand and other identifying parameters. Therefore, with this standardised building typology, a data model can be constructed, with standardised heating demand and emissions for every building unit. This paper uses this underlying data model to simulate building renovation. The data model is further explained in Section 1.

The GEWISS simulation team followed the rapid prototyping methodology and started with mock-ups based on multi-agent simulation tools [2]. The current approach is to rank all buildings in the data model and stochastically renovate ranked buildings in order according to a global renovation rate, for every year of the 
simulation run. The building's ranking score is affected by the following impact factors:

- Building type factor, maps the impact factor for different building types (IWU for residential and an Ecofys typology for non-residential buildings (Ecofys.com is GEWISS project partner)) for each year of the simulation.

- Location factor, mapping of the building's spatial allocation for each year of the simulation. Either on the level of districts, quarters or statistical areas in Hamburg to map socio-economic factors.

- Property factor, maps different impact factors for private, cooperative, company-owned and public owned property for each year of the simulation.

- Heritage protection factor, maps factors for buildings under monument protection for each year of the simulation.

To calculate scoring value, above parameters are factored only globally for every building in the current year of the simulation and are multiplied with some inherent factors, to give every building a rank. After the ranking process, a predefined percentage of the ranked buildings are stochastically renovated to a higher building standard. The current approach is limited in its flexibility, as the impact factors affecting the ranking score are based on single criteria. Therefore, only making it possible to affect the ranking of e.g. one-family houses and houses in the quarter Altona but not just 'single family houses in Altona'. Also, the current approach does not allow for temporal restrictions on selection of buildings, or the input of possible investment scenarios.

Based on the observation that the scenario modelling abilities are crucial for the applicability in studying what-if questions under various assumptions, this paper proposes a novel solution to the current limitations. First, the simulation would be user manipulatable, i.e. the user would be able to temporally and spatially identify a subset of buildings. Then, using a multi-criteria selection algorithm, the ranking of this building subset would be modified, within the entire set of buildings. This approach to referred to as the "Modifier Approach", further explained in Section 2.1. Finally, an outlook towards optimization of renovation to meet user criteria is provided in Section 3, along with suggestions for future research.

\section{Initial Parameters}

To understand the problem statement the GEWISS simulation aims to solve, a look at the available data model must be taken. The following subsection explores the foundational data model our simulation uses. Further on, the simulation's inherent properties are also explained with an outro towards the renovation thresholds in the later subsections.

\subsection{Available and Assumed Data}

The data model in consideration contains all current buildings in Hamburg as a unique entry. Their data is classified with the following attributes:
1. $B_{\mathrm{ID}}$
-Building Identifier (unique ID)
2. $B_{\text {ort }}$
-Location (District, Borough)
3. $B_{\mathrm{jahr}}$
-Construction year (estimated IWU epoch)
4. $B_{\text {typ }}$
-Building type (residential/non-residential)
5. $B_{\mathrm{ss}}$
Current renovation level (standard of renova tion)
6. $B_{\text {own }}$-Ownership of Building (Private, Public)
7. $B_{\mathrm{hs}}$-Current heating system (Gas, District heating, etc)
8. $B_{\mathrm{fw}} \quad$-Distance to the nearest district heating connection
9. $B_{\text {DMS }}$-Heritage protection status

An important parameter is current renovation level $B_{\mathrm{ss}}$ of a building. In our model, the renovation level is classified into 3 stages:

- 0 : Unrenovated state

- 1: Renovated to EnEV 2014 standards

- 2: Renovated to Passive house standards

Thereby, a renovation level of 0 means that the building has never been renovated since it was built, a renovation level of 1 means that the building has been renovated according to the German Passive House Standard which is also defined in the latest German energy saving ordinance (EnEV 2014) [7].

The simulation would operate on the selection of buildings using the above written parameters, as well as inherent factors that the simulation operates upon. These factors are explained in the following subsection.

\subsection{Inherent Simulation Operators}

The simulation operates upon two assumptions that are made of the simulated environment [2].

1. Age incentive $I_{\mathrm{rp}}-$ As age since last renovation increases, renovation chance of a building increases. Conversely; newly renovated buildings will not be considered for renovation again immediately.

2. Neighborhood Effect $I_{\mathrm{n}}-\mathrm{A}$ building's renovation affects the renovation chance of its neighbors. If a building is neighbored by renovated buildings, its renovation chance also increases.

These inherent operators define the environment of the simulation. They provide a base ranking to each build- 
ing that is then modified by user selected modifiers. Finally, depending on user prioritised modifiers, the selected buildings would then be passed through the selected renovation threshold. These are explained in the following subsection.

\subsection{Renovation Thresholds}

The simulation also relies on the following rates to change the state of considered buildings:

1. Global renovation rate $R_{\mathrm{g}}$ - Percentage of the buildings that would be renovated.

2. Passive house rate $R_{\mathrm{p}}$ - Percentage of the renovated houses that will be renovated to the passive house standard $\left(B_{\mathrm{ss}}=2\right)$

3. Rate of change of heating system $R_{\mathrm{h}}$ - Percentage chance of the change of heating system.

Using the criteria and factors explained above, the next section delves further into the proposed simulation logic.

\section{Proposed Approach}

The simulation engine is designed as a combination of multiple components. The simulation engine accepts data from the user through the "scenario editor" GUI, which supplies the simulator with the user scenarios. The simulator then outputs one list containing ranked renovation candidates. These buildings are then passed through the optimizer, that decides the optimal renovation levels for each building according to the renovation strategy. This process is pictured in figure 2 .

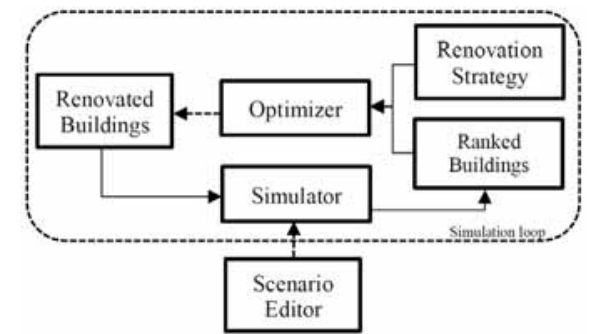

Figure 2: Proposed simulation logic. The simulation runs the ranking and renovation process for each simulation year.

Every year of the simulation run, every unique building is assigned a renovation score $\left(S_{\mathrm{i}}\right)$. The simulation ranks the buildings using the formula outlined here:

$$
S_{\mathrm{i}}=I_{r p} * I_{n}
$$

The simulation and optimizer logic are explored in detail below, with the help of an illustrative example.

\subsection{Modifier Approach}

The scenario editor uses GUI elements we call modifiers. Modifiers are criteria-based selectors, selecting a set of buildings according to user-specified criteria and modifying the rank of these buildings within the simulation. They are active for a specified finite period within the simulation. When a building satisfies the modifier criteria, the building rank of a building is altered by a user assigned modifier impact factor $\left(I_{\mathrm{m}}\right)$, in addition to the inherent operators in the simulation. Equation (2) demonstrates renovation score $S_{\mathrm{i}}$ for a building that matches criteria that was selected for modifiers $m_{1}, m_{2}$, $m_{3} \ldots m_{\mathrm{n}}$, during set time frame.

$$
S_{\mathrm{i}}=I_{r p} * I_{n} * I_{m_{1}} * I_{m_{2}} * I_{m_{3}} \ldots I_{m_{n}}
$$

Where $I \mathrm{~m}$ refers to the respective modifier impact factor set by the user. The primary objective of this approach is to allow the user to manipulate the simulation, to model stories that can represent complex real-world events.

These stories can represent financial promotion, legal incentives, or target emissions to be achieved. The following example is considered:

\section{"All unrenovated public buildings built before 1960 are renovated from gas to district heating $(F W)$ in 2025 "}

This user story uses the following parameters- renovation level $\left(B_{\mathrm{ss}}\right)$, ownership of Building (Bown), construction year $\left(B_{\text {jahr }}\right)$, heating system implemented $\left(B_{\mathrm{hs}}\right)$ and the time period of incentive. These parameters are clustered together and fed into the simulation engine in the form of a modifier. Assuming the modifier impact factor $\left(I_{\mathrm{m} 1}\right)$ to be 2 , the renovation score $\left(S_{\mathrm{i}}\right)$ of buildings selected by the modifier can be represented by:

$$
S_{\mathrm{i}}=I_{r p} * I_{n} * 2
$$

To illustrate the renovation score with the example given above, table 2 is input to the simulator as building data.

\begin{tabular}{|l|l|l|l|l|}
\hline $\begin{array}{l}\text { Build- } \\
\text { ing ID }\end{array}$ & $\begin{array}{l}\text { Renova- } \\
\text { tion level }\end{array}$ & Ownership & $\begin{array}{l}\text { Construction } \\
\text { Year }\end{array}$ & $\begin{array}{l}\text { Heating } \\
\text { system }\end{array}$ \\
\hline B1 & 0 & Private & 1960 & District \\
B2 & 0 & Public & 1920 & Gas \\
B3 & 1 & Public & 1970 & Gas \\
B4 & 2 & Private & 2000 & District \\
B5 & 0 & Public & 1940 & Gas \\
\hline
\end{tabular}

Table 2: Illustrative data input into simulation.

When the simulation is in the year 2025, the renovation ranking of selected buildings would be modified, which in this case are B2 and B5. Assuming values of Inherent operators, table 3 demonstrates renovation score for the above buildings for simulation year 2025 .

As can be seen in the above example, modifiers are able to prioritize buildings that match user specified criteria. One simulation run can take multiple modifiers into consideration, allowing the user high levels of control over the way the simulation ranks houses. 


\begin{tabular}{|l|l|l|l|l|}
\hline $\begin{array}{l}\text { Build- } \\
\text { ing ID }\end{array}$ & $\begin{array}{l}\text { Renovation } \\
\text { score }\end{array}$ & $\begin{array}{l}\text { Neighborhood } \\
\text { effect }\end{array}$ & $\begin{array}{l}\text { Modi- } \\
\text { fier 1 }\end{array}$ & $\begin{array}{l}\text { Renovation } \\
\text { score }\end{array}$ \\
\hline B1 & 1.2 & 1 & NA & 1.2 \\
B2 & 1.3 & 1 & 2 & 2.6 \\
B3 & 0.8 & 2 & NA & 1.6 \\
B4 & 0.5 & 1 & NA & 0.5 \\
B5 & 1.9 & 1 & 2 & 3.8 \\
\hline
\end{tabular}

Table 3: Illustrative ranking from simulation. Inherent factors are as- sumed values. B2 and B5 are ranked highest; modifiers are able to prioritise user selected buildings.

Taking the inherent operators into account, the simulation allows for differing values renovation rank every simulation year.

Modifiers are a form of reduced processing strategy, implemented to allow control over the decision overhead of the simulation, by allowing for multiple criteria ranking. The following section explains the steps the optimization engine takes to renovate buildings against a user set renovation strategy and concludes with an outlook.

\section{Conclusion \& Outlook}

\subsection{Renovation Strategies \& Optimization}

The user might also like to explore financial investment scenarios, or even heating demand/emission reduction scenarios. To perform these simulations, the ranked buildings must be evaluated against the renovation strategy, and then different renovation paths must be compared. This task is assigned to the optimizer. The optimizer uses global renovation rate $R 5$, passive house rate $R$ ) and heating system change rate $R$ ) as renovation thresholds. As seen in figure 2, the optimizer takes in the ranked building list from the simulation, and then passes them through the renovation thresholds optimally to match the user set renovation strategy. Given below is a list of renovation strategies considered:

1. Money invested annually to incentivize renovation.

2. Heating demand reduction

3. $\mathrm{CO}_{2}$ emission reduction

In the case of financial incentive, the user would specify a lump sum amount of money that would be invested into the city to renovate buildings through the simulation run. Using modifiers, the user can ensure that selected buildings are likelier to receive financial support. The end result in this case would show reduction in heating demand and $\mathrm{CO} 2$ emissions. When the strategy is to reduce heating demand and $\mathrm{CO} 2$ emissions, the user could specify targets that the simulation must achieve. The end result in this case would show money invested over the simulation run.
Depending on the renovation state of the building, there could be up to 2 state changes $(0 \rightarrow 1,1 \rightarrow 2)$ and/or a change in the heating system of the house. All these state changes result in differing levels of cost, and demand/emissions reduction.

Furthermore, these state changes are controlled with the renovation threshold described earlier. The optimizer must then, considering the set renovation strategy, find the best candidates in the ranking list to pass through the renovation thresholds.

\subsection{Outlook to Future Development}

Considering the optimization search space outlined in the previous subsection, the authors suggest the use of metaheuristics, with a preference towards ant colony optimisation (ACO). This would allow the optimizer to roam the search space for optimal solutions parallelly, reducing processing time and simulation overhead.

Future development might consider the implementation of renovation thresholds and strategies at a local scale, as the current implementation defines renovation thresholds and strategies globally. Using exclusion sets, the user would be able to restrict different renovation strategies spatially and temporally, allowing full control over the simulation results.

Finally, making the data model format open source might aid other researchers in the development of expert simulation and visualisation tools for other German cities.

\section{References}

[1] Balaras CA, et al. "European residential buildings and empirical assessment of the Hellenic build- ing stock, energy consumption, emissions and potential energy savings." Building and environment 42.3 (2007): 1298-1314.

[2] Preisler T, et al. "Towards an agent-based simula- tion of building stock development for the city of ham- burg." Computer Science and Information Systems (FedCSIS), 2017 Federated Conference on. IEEE, 2017.

[3] http://www.hamburg.de/energiewende/waermekataster/

[4] http://suche.transparenz.hamburg.de/dataset/alkisliegens chaftskarte-ausgewahlte-daten-hamburg

[5] Diefenbach N, et al. "Deutsche Wohngebäudety- pologie - Beispielhafte Maßnahmen zur Verbesserung der Energieeffizienz von typischen Wohngebäuden," IWU - Institut Wohnen und Umwelt, Tech. Rep., 2015. [Online]. Available: http://www.building-typology.eu/downloads/public/docs/brochure/DE_TABULA_TypologyBrochure_IWU.pdf

[6] Dochev I, et al. "Assigning IWU building types to buildings in the Hamburg ALKIS," 2017. 